\title{
KOMUNIKASI INTERPERSONAL PENGGUNA JALAN DALAM WUJUD KARYA CIPTA MUSIK BERJUDUL "BANGJO"
}

\author{
Raden Aditya Nugraha ${ }^{1}$, M. Yoga Supeno ${ }^{2}$ \\ ${ }^{1}$ Dinas Pendidikan dan Kebudayaan Kota Bandar Lampung \\ Email: yongkimahendra24@gmail.com \\ ${ }^{2}$ Staf Pengajar Jurusan Etnomusikologi ISI Yogyakarta \\ Email:yogasupeno@gmail.com
}

\begin{abstract}
Abstrak
Karya cipta musik etnis selalu berhubungan dengan fenomena-fenomena yang dalam aktivitas masyarakat, menjadi sumber ide penciptaan sehingga secara estetis dapat dinikmati oleh audiens dan secara akademis dapat memahami tulisan. Konteks komunikasi maka fenomena merupakan tanda yang bukan sekedar imajinasi tetapi harus ditransmutasikan dalam wilayah intramusikal, seperti halnya fenomena komunikasi intrapersonal pengguna jalan dalam merespon peraturan traffic light dan pemakai jalan lainnya. Menjadi sebuah fenomena menarik karena secara ideal seharusnya peraturan berfungsi mengikat penggunanya tetapi fakta justru seingkali terjadi dinamika-dinamika perilaku yang memberikan adanya pelanggaran-palanggaran subtansi berkendara. Melakukan transmutasi dalam penciptaan musik etnis memberikan dampak terhadap metode penelitian penciptaan, sehingga metode karya cipta ini didahului dengan penelitian yang mengungkapkan pengalaman manusia melalui fenomenologi sedangkan wilayah penciptaan mempergunakan transmutasi (mengubah obyek ke obyek lain), pengumpulan intramusikal, ekspolrasi-improvisasi dan refleksi. Hasil penelitian bahwa kesadaran berlalu lintas sangat dipengaruhi oleh manajeman seseorang dalam mengelola waktu, dan secara hakekat tanda warna pada lampu menjadi sebuah peringatan dalam manajemen perilaku berlalu lintas. Waktu dan dinamika dalam wilayah penelitian menjadi point view yang kemudian ditransmutasikan dalam wilayah pemilihan kawasan intramusikal nada-nada yang akan digunakan menjadi sebuah karya musik etnis berjudul "Bangjo"
\end{abstract}

Kata kunci: Komunikasi, intrapersonal, Bangjo

\begin{abstract}
Music copyright works are always related to phenomena in people's activities, become a source of ideas that can be enjoyed by the audience and can be understood by the audience. In the context of communication, the phenomenon is a sign that is not only read but must be transmitted in an intramusical area, such as the phenomenon of road users' intrapersonal communication in responding to traffic light regulations and road users. It becomes an interesting phenomenon because ideally regulations should serve to bind users, but the fact is that there are behavioral dynamics that give driving substance violations. Carrying out transmutations in terms of ethnic ethics, so that the impact on research methods, so that the method of this creative work is preceded by expressing human experience through the phenomenology of a region that uses transmission (changing objects to other objects), influencing intramusical, improvisation and reflection. The result of this research is that traffic awareness is very much needed by someone's management in time, and in essence the color marks on the lights become a warning in traffic behavior. The time and dynamics in the research area become points of view which are then transmitted in the intramusical area of the tone to be used as an ethnic music work entitled "Bangjo"
\end{abstract}

Keywords: Communication, intrapersonal, Bangjo 


\section{A. Latar Belakang}

Karya cipta musik etnis tidak bisa lepas dari fenomena yang sering menjadi sumber ide penciptaan, tetapi mentransformasikan fenomena-fenomena tersebut menjadi sebuah garapan yang mempunyai nilai kebaruan sehingga secara estetis dapat dinikmati oleh audiens dan secara akademis dalam tulisan mudah dipahami merupakan sebuah tantangan yang harus dihadapi oleh pencipta. Konteks komunikasi, maka memposisikan fenomena-fenomena dalam posisi tanda yang harus diberi label-label makna merupakan sebuah langkah awal yang wajib dilakukan dalam arena penciptaan berdasarkan penelitian, salah satu fenomena unik dalam aktivitas masyarakat sehari-hari adalah komunikasi intrapersonal pengguna jalan dalam memberikan respon terhadap keberadaan traffic light dan sesama pemakai kendaraan.

Traffic light dalam persimpangan atau perempatan sangat penting untuk mengatur lalu lintas di jalan raya, khusus di daerah terpencil fungsi traffic light masih sangat kurang diperhatikan dan disadari oleh masyarakat penggunanya. Terlebih pada saat malam hari, banyak pengguna jalan raya yang tidak menaati karena dirasa jalanan sudah mulai sepi dan banyak yang takut untuk berhenti. Masyarakat beranggapan bahwa pada malam hari khususnya diatas jam 22.00 traffic light biasanya dijadikan tempat kriminal, seperti perampokan, dan tidak asusila. Sedangkan pada siang hari traffic light sering digunakan untuk mencari nafkah oleh para pedagang asongan, seniman jalanan, dan tuna wisma.

Pada dasarnya traffic light merupakan media bagi seluruh pengendara agar terciptanya ketertiban dan kedisiplinan dalam berlalu lintas, tetapi sering kali terjadi peristiwa pelanggaran, kelalaian oleh pengguna jalan. Beberapa contoh pelanggaran yang sering terjadi seperti: menerobos traffic light warna merah, mempercepat laju kendaraan ketika traffic light warna kuning. Fenomena tersebut dapat berdampak pada kecelakaan lalu lintas, sistem transportasi menjadi tidak beraturan. Selain itu pengendara dilarang melakukan kegiatan yang mengganggu keselamatan pengguna jalan dan dirinya sendiri: Contohnya menggunakan alat komunikasi saat berkendara. Pada saat traffic light bertanda merah, banyak pengendara tidak sabar untuk jalan padahal tanda belum berubah menjadi warna hijau.

Traffic light berdasarkan konvensi merupakan tanda yang wajib ditaati bagi seluruh pengguna jalan, tetati sebagian pengendara tidak memiliki kesabaran 
dalam berlalu lintas. Ketidaksabaran tersebut dipengaruhi oleh emosi atau ekspresi jiwa pengendara. Beberapa contoh ekspresi jiwa terhadap tanda traffic light adalah gelisah dan terburu-buru, selain itu factor cuaca juga menjadi pengaruh pada aktivitas lalu lintas masyarakat.

Diskursus mengenai musik merupakan relasi bolak balik antara fungsi dan makna simbolik. Cassier (dalam Meriam: 1964) menyatakan bahwa seni dapat di definisikan sebagai bahas simbolik dimana dia mengutip dari pandangan Aristoteles bahwa seni sifatnya adalah imitative yakni fungsi utama kesenian bersifat mimetik. Cassier menambahkan bahwa kesenian adalah karakteristik yang berupa luapan emosi dan nafsu yang dibentuk ke dalam sebuah fungsi secara utuh dimana setiap bagian mengeksperiskan perasaan atau emosi. Secara sederhana seni dapat dikatakan reproduksi yang bersifat imitatif: kedalaman dari inerlife perasaan dan emosi. Seni termasuk musik adalah unsur-unsur simbolik yang harus dibedakan dari beberapa pendekatan.

Langer (dalam Meriam: 1964) menyatakan bahwa musik adalah bentuk yang bermakna, dan makna tersebut adalah symbol sesuatu yang ingin diungkapkan merupakan objek rasa dengan struktur dinamika yang dapat mengungkapkan bentuk pengalaman yang tidak bias disampaikan melalui bahasa. Perasaan, kehidupan, gerakan, dan emosi berhubungan dengan bentuk pengalaman simbolik.

Berdasarkan fenomena mengenai traffic light secara tekstual dapat diambil objek material berupa eksperesi simbolik pengendara. Ekspresi simbolik merupakan bagian dari fungsi, nilai guna objek dalam keilmuan Antropologi. Uraian singkat mengenai fenomena di atas mengilhami dalam penciptaan karya musik dengan judul Traffic light: Musik Ekspresi Simbolik.

\section{Ilmu Bentuk Musik}

Karl-Edmund Prier SJ, Ilmu Bentuk Musik. (Yogyakarta: Pusat Liturgi, 1996). Menjelaskan tentang struktur komposisi dan bentuk komposisi yang mengarahkan seseorang untuk membuat sesuatu yang berhubungan dengan psikologi sosial, dan kebudayaan dalam analisis musik. Prier dalam Ilmu Bentuk Musik memprioritaskan pada analisis musikalnya dari pada aspek psikologi sosial. Berbeda dengan Vincent McDemothtt, Imagi-Nation Membuat Musik Biasa Menjadi Luar Biasa. (Yogyakarta: Art Musik Today, 2013). Menjelaskan tentang bagaimana seorang komposer membuat musik sederhana menjadi istimewa dengan menggunakan 
teknik-teknik baru dalam membuat komposisi musik yang diinginkan.

Komposisi ataupun analisis struktural musik yang disampaikan oleh Prier dan Demothtt merupakan unsur-unsur simbolik dimana musik dipandang sebagai sebuah seni dengan aturan eksistensi bunyi yang didengar. Hal ini memberikan makna bahwa cipta karya musik harus mempunyai landasan dalam sisi ekspresi simbolik. Moris menyatakan bahwa tanda bersifat indeksikal yaitu memberikan makna yang berhubungan dengan pluralitas karena tanda dapat didefinisikan baik sebagai sesuatu ataupun prilaku yang bermakna kepada orang yang menggunkannya. Sesuatu yang dikatakan sebagai tanda atau simbol memiliki berbagai bentuk fisik sebagai bentuk objek material seperti warna, bunyi, gerakan, dan emosi. Hal ini juga diperkuat dengan pernyataan Susan K. Langer menyatakan bahwa simbol bukanlah wakil dari objeknya melainkan sarana untuk menginterpretasikan objek tersebut.

\section{Fungsionalisme}

Fungsionalisme bahwa eksplorasi ciri sistemik budaya memerlukan orientasi teori atau dictum metodologis, hal ini memiliki dampak terhadap struktur budaya dalam masyarakat sebagai sebuah sitem yang utuh. Fungsi keutuhan budaya mengandung makna bahwa kebudayaan merupakan suatu bagian yang kompleks, Merton (dalam Kaplan: 2002) menjelaskan bahwa keutuhan fungsional masyarakat memiliki arti suatu fungsi mempunyai kontribusi terhadap fungsi yang lain. Merton juga menjelaskan tentang postulat fungsionalisme universal yaitu bahwa segala unsur budaya melaksanakan suatu fungsi dan tidak ada satupun unsur budaya yang mampu melaksanakan fungsi yang sama. Upaya merton untuk menjelasakan kosep fungsi diperkenalkanlah pembedaan antara fungsi manifes dan fungsi laten. Fungsi manifes adalah konsekuensi objektif yang memberikan sumbangan pada penyesuaian yang dikehendaki dan disadari oleh partisipan tersebut sedangkan fungsi laten adalah konsekuensi objektif yang dikehendaki oleh masyarakat. Postulat fungsional ini berlaku bolak balik tergantung dari masyarakat.

\section{B. Metode Penelitian Penciptaan}

Karya cipta musik tidak lepas dari penelitian, karena musik tidak bisa lahir dari sebuah imajinasi saja tetapi bagaimana kontruksi sebuah imajinasi tertuang dalam nilai penelitian sehingga dalam penciptaan ini diawali dengan penelitian. Fenomena pengguna jalan dalam bentuk-bentuk ekspresi simbolik ketika merespon 
situsional dalam traffic light merupakan sebuah fenomena yang hanya bisa dilahirkan dari pengalaman seseorang atau pengguna jalan sehingga dalam penelitian ini menggunakan kualitatif fenomenologi untuk mendapatkan data-data pada kawasan emic, adapun tahapan pengumpulan data terdiri dari observasi dan wawancara, kemudian dilakukan analisa data yang menjadi point penting dalam wilayah penciptaan Creswell (2002: 18) menjelaskan bahwa fenomenologi merupakan jenis penelitian kualitatif dimana hakekat pengalaman seseorang menjadi salah satu faktor penting dalam menelaah objek material. Studi fenomenologi memberikan langkah awal pada wilayah etic yaitu penciptaan yang terdiri dari transmutasi, pengumpulan data intramusikal-ekstramusikal, eksplorasiimprovisasi, refleksi. Tahapan-tahapan tersebut dapat dilihat dari skema di bawah ini. 


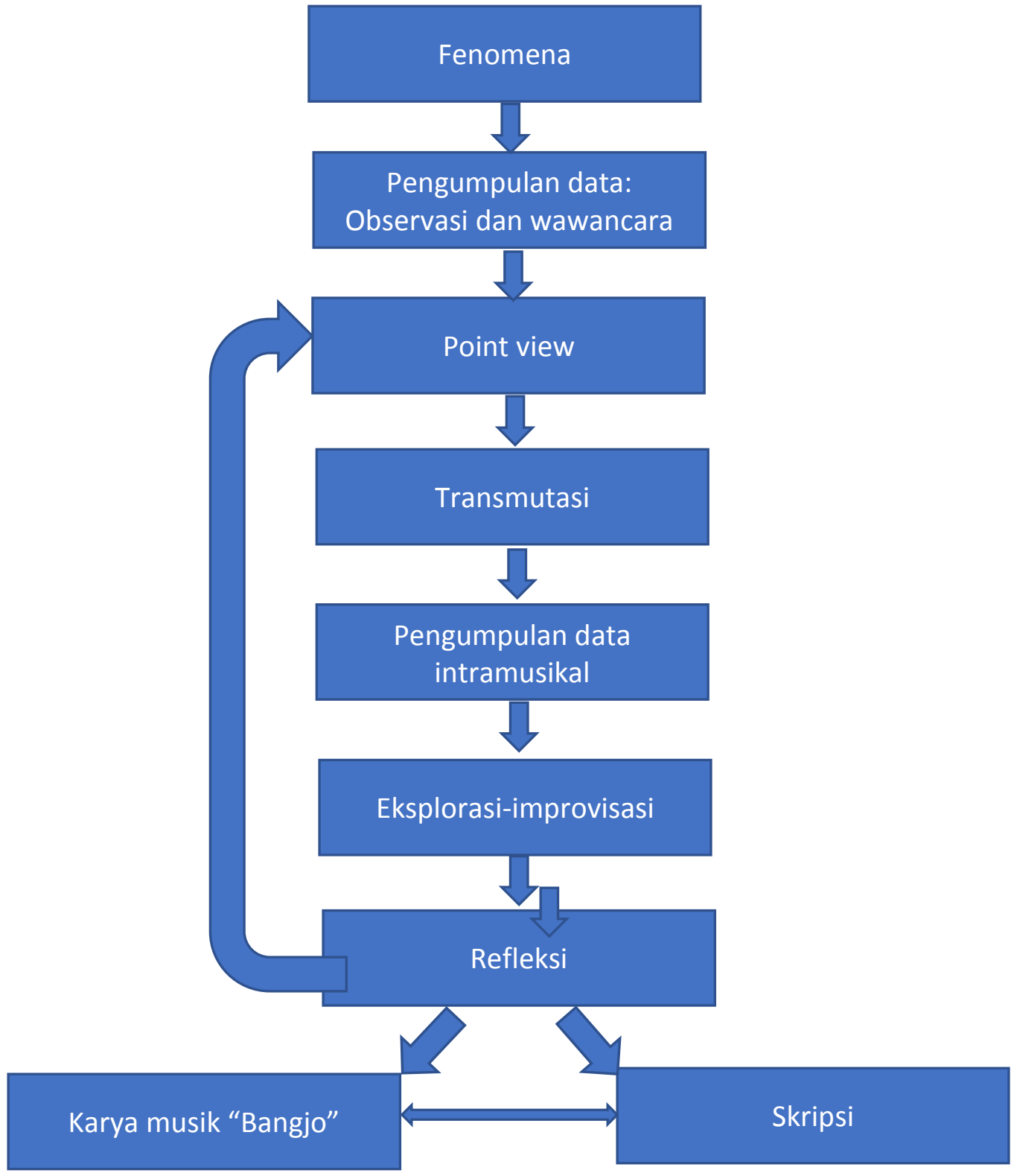

Gambar 1

Skema tahapan penciptaan yang didahului dengan penelitian

C. Hasil dan Pembahasan

$$
\text { Komunikasi intrapersonal }
$$

pengguna jalan dalam merespon tanda dan pemakai jalan lain mempunyai makna bahwa perilaku terbagi dalam aspek dinamika dan terhadap waktu, simbol warna traffic light itu sendiri kemudian dimaknai sebagai proses perjalanan manusia. Sebagai makhluk individu dan makhluk sosial, manusia berusaha untuk mengembangkan kehidupannya, serta selalu bergerak dinamis ke arah suatu tujuan yang diinginkannya. Dalam 
prosesnya, manusia selalu mengalami banyak rintangan, artinya perjalanan yang dihadapi oleh manusia tidak semata-mata berjalan dengan mulus. Traffic light dimaknai sebagai simbol warna hidup karena menurut pemahamannya kehidupan tidak selalu berwarna hitam dan putih atau baik dan buruk, akan tetapi ada warna yang lain yang mengikutinya dan menjadi proses untuk mencapai tujuan. Tiga warna dalam traffic light menjadi simbol tertentu dan memiliki pemahaman yang berbeda dalam kehidupan. Warna merah menghadirkan sesuatu hal yang tegas dan berani, Warna hijau menghadirkan rasa santai, kedamaian dan ketenangan jiwa dan warna kuning dimaknai sebagai suatu kebimbangan, persimpangan dan keberanian reaksi. Oleh karena itu dalam wilayah penelitian proses skematik yang terjadi adalah sebagai berikut:

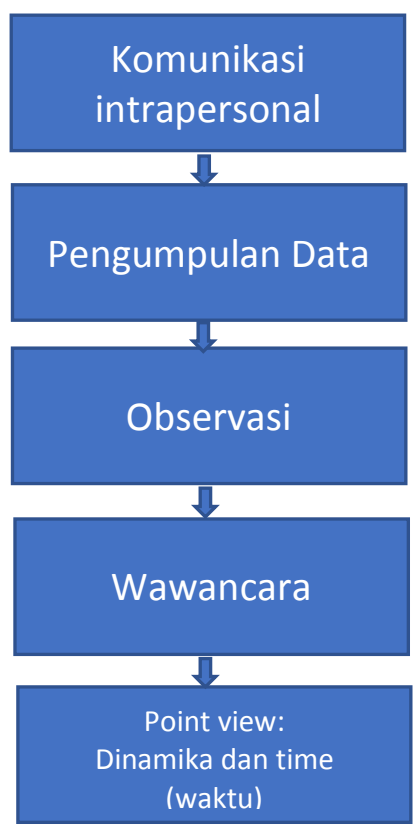

Gambar 2

Skema wilayah emik

Konteks fungsional dan komunikasi bahwa satu warna muncul entah itu merah, hijau atau kuning akan muncul pula suatu reaksi yang berbeda dari setiap pelaku lalulintas. Terkadang secara alami ada beberapa pelaku yang secara dinamis mengikuti aturan yang ada namun kekontrasan pun tidak jarang terjadi, warna yang muncul tidak dimaknai seperti yang seharusnya. Apabila diperhatikan dan diamati traffic light merupakan suatu simbol yang memaksa dan menjadi sebuah keharusan bagi pengguna jalan raya, di mana ketika lampu itu menyala semua 
pengguna jalan raya harus mematuhi seolah-olah jalan milik traffic light semata. Dialah yang mengatur segala aktifitas di jalan raya, tetapi itu bukan sesuatu yang salah atau tidak baik karena pada dasarnya traffic light memang dikondisikan bersifat memaksa untuk mengatur arus lalu lintas demi kebaikan seluruh pengguna jalan raya agar aktivitas jalan raya berjalan lancar.

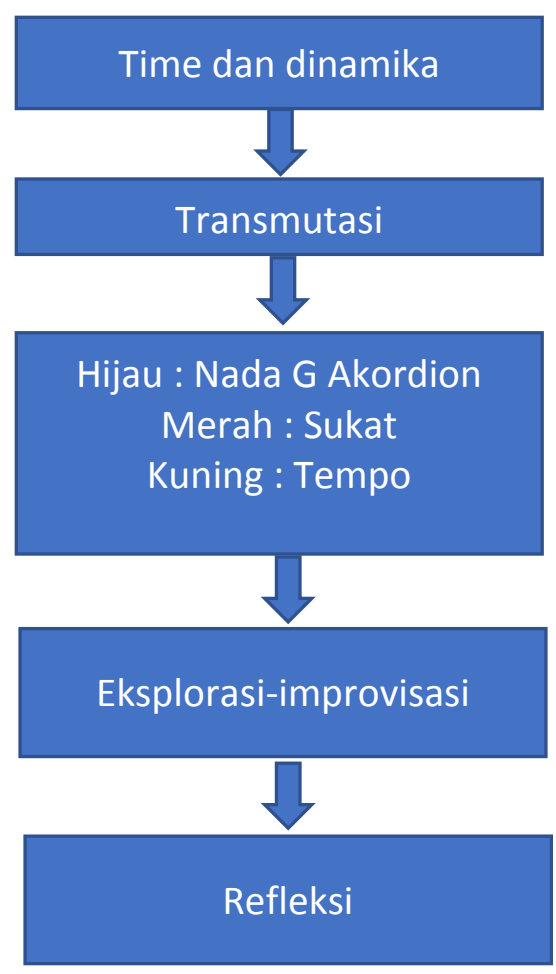

Skema 3

Wilayah penciptaan

Karya ini terdiri dari empat bagian yang menggambarkan warna merah, hijau, kuning dan merah kembali. Warna merah digambarkan sebagai suatu keadaan titik jenuh, tidak bergerak, dan hubungan sosial yang kurang baik dengan orang lain. Warna hijau digambarkan sebagai suatu keadaan tanpa hambatan, jalan terus, semangat yang besar. Selanjutnya warna kuning dimaknai sebagai kebimbangan gejolak hati, persimpangan, dan hati-hati. Kemudian warna merah yang kedua merupakan akibat dari kesalahan dan penyesalan. Selanjutnya sejauh mana sumber itu akan diolah dan diciptakan kembali sangat tergantung pada intensi, mood, olahan perasaan dan gagasan yang dituangkan dalam komposisi.

\section{Introduksi}

Bagian introduksi ini merupakan penggambaran simbol dari tiga warna traffic light. Dimulai dari suara trombone, 
trompet, dan perkusi. Warna hijau disini dilambangkan dengan permainan akordion yang memainkan nada minor yang terus berjalan dengan menekan akord G. Bass elektrik disini sebagai pengikat nada atau latar musiknya, alasannya hijau adalah warna yang menenangkan, yang menyegarkan sistem saraf. Warna ini menghadirkan rasa santai, kedamaian, dan ketenangan jiwa.

\section{Bagian I}

Dibagian satu ini merupakan pelambangan simbol warna merah. Dibagian ini durasi waktu komposisi warna merah lebih lama karena berdasarkan penelitian dan pengamatan di traffic light diketahui bahwa durasi atau waktu hidup lampu yang bewarna merah itu lebih lama dari pada warna lain nya itulah hal yang melandasi warna merah lebih lama durasinya dibandingkan lampu yang lainnya. Dalam komposisi ini warna merah dilambangkan dengan permainan sukat-sukat ganjil dan lebih dominan dimainkan oleh intrumen perkusi.

\section{Bagian II}

Bagian ini merupakan bagian yang menceritakan tentang warna hijau yang melambangkan suasana segar tenang dan senang ketika pengguna jalan raya melewati lampu traffic light yang berwarna hijau. Ketika kita melewati warna hijau pun semua kendaraan yang ada dijalan tidak ada yang berhenti mereka semua berjalan. Suasana tersebut digambarkan dengan seluruh instrumen berbunyi dan saling mengisi. Dengan menggabungkan harmonisasi lewat isntrumen bonang yang bermain ritme 4/4 dan 7/4. Di ikuti trumpet dan trombone yang saling bermain dengan harmonisasi nada, di sini akordion dan gambus sebagai filler dari permainan trombone dan trumpet.

\section{Bagian III}

bagian ini merupakan gambaran dari simbol warna kuning, di mana arti dari warna tersebut merupakan simbol peringatan atau perintah untuk berhati- hati. Fenomena menarik dalam bagian ini adalah ketika lampu tanda warna kuning sudah menyala pengendara akan menabah kecepatannya untuk segera melewati traffic light tersebut. Pada bagian ini musik yang dibuat lebih condong pada suasana hati pengendara yang bimbang ketika melihat warna kuning dengan permainan beberapa instrumen yang memainkan tempo lambat dan cepat.

\section{Simpulan}

Komunikasi intrapersonal merupakan kkspresi simbolik pengendara merupakan sebuah respon ketika melaksanakan 
aktivitas berkendara, dinamika yang terjadi di jalan raya merupakan dampak yang terjadi dalam pengelolaan waktu dan dinamika sosial. Waktu dalam perspektif intramusikal dapat diintepretasikan dalam wilayah tempo, sedangkan dinamika komunikasi dapat menjadi idiom-idiom yang menjadi landasan dalam mendeskripsikan simbol-simbol dalam bentuk abstraksi bunyi sehingga menjadi karya musik yang mengintepretasikan peristiwa atau sebuah kasus yang terjadi dalam kehidupan sehari-hari.

\section{E. Daftar Pustaka}

Banoe, Pono. 2003. Pengantar Pengetahuan Harmoni. Yogyakarta : Kanisius.

Bassano, Marry. 2009. Terapi Musik dan Warna. Yogyakarta: Rumpun.

Djohan. 2009. Psikologi Musik Yogyakarta: Best Publisher.

Ekman, Paul. 2011. Membaca Emosi Orang. Yogyakarta: Think Yogyakarta.

Hardjana, Suka. 2003. Corat-coret Musik Komtemporer Dulu dan Kini. Jakarta : Ford Foundation dan Masyarakat Seni Pertunjukan Indonesia.

Hawkins, Alma M. 1988.Aspek-aspek Koreografi Kelompok, terj. Y.
SumandiyoHadi. Yogyakarta :Lembaga Kajian Pendidikan dan Humaniora Indonesia.

Marianto, M. Dwi. 2006. "Metodologi Penciptaan Seni" dalam Surya Seni: Jurnal Penciptaan dan Pengkajian Seni Volume 2 No 1.

McDermott, Vincent. 2013. Imagi-Nation : Membuat Musik Biasa Jadi Luar Biasa. Terj. Natha H.P. Dwi Putra. Yogyakarta : Art Musik Today.

Moeliono, Anton M.Kamus Besar Bahasa Indonesia. Jakarta: Balai Pustaka, 1999.

Prier, Karl-Edmund. 1996. Ilmu Bentuk Musik. Yogyakarta : Pusat Musik Liturgi.

Sabaruddin. 2012.Lampung Pepaduan Dan Saibatin/pesisir. Jakarta: Buletin Way Lima Manjau.

Soeharto,M. 1986. Belajar Membuat Lagu. Jakarta : PT Gramedia. 
